\title{
Investigating associations between intestinal alterations and parasite load according to Bifidobacterium spp. and Lactobacillus spp. abundance in the gut microbiota of hamsters infected by Leishmania infantum
}

\author{
Fabine Correia Passos", Marcelo Biondaro Gois², Adenilma Duranes Sousa', \\ Ananda Isis Lima de Marinho', Laura Corvo ${ }^{3}$, Manoel Soto ${ }^{3}$, Manoel Barral-Netto ${ }^{4}$, \\ Aldina Barral ${ }^{4}$, Gyselle Chrystina Baccan ${ }^{1 /+}$ \\ ${ }^{1}$ Universidade Federal da Bahia, Instituto de Ciências da Saúde, Departamento de Bioquímica e Biofísica, Salvador, BA, Brasil \\ ${ }^{2}$ Universidade Federal do Recôncavo da Bahia, Centro de Ciências da Saúde, Santo Antônio de Jesus, BA, Brasil \\ ${ }^{3}$ Universidad Autónoma de Madrid, Facultad de Ciencias, Consejo Superior de Investigaciones Científicas, \\ Centro de Biología Molecular Severo Ochoa, Departamento de Biología Molecular, Madrid, Spain \\ ${ }^{4}$ Fundação Oswaldo Cruz-Fiocruz, Centro de Pesquisas Gonçalo Muniz, Salvador, BA, Brasil
}

BACKGROUND Visceral leishmaniasis (VL) is a tropical neglected disease with high associated rates of mortality. Several studies have highlighted the importance of the intestinal tract (IT) and gut microbiota (GM) in the host immunological defense. Data in the literature on parasite life cycle and host immune defense against VL are scarce regarding the effects of infection on the IT and GM.

OBJECTIVES This study aimed to investigate changes observed in the colon of Leishmania infantum-infected hamsters, including alterations in the enteric nervous system (ENS) and GM (specifically, levels of bifidobacteria and lactobacilli).

METHODS Male hamsters were inoculated with $L$. infantum and euthanised at four or eight months post-infection. Intestines were processed for histological analysis and GM analysis. Quantitative polymerase chain reaction (qPCR) was performed to quantify each group of bacteria: Bifidobacterium spp. (Bf) and Lactobacillus spp (LacB).

FINDINGS Infected hamsters showed histoarchitectural loss in the colon wall, with increased thickness in the submucosa and the mucosa layer, as well as greater numbers of intraepithelial lymphocytes. Forms suggestive of amastigotes were seen inside mononuclear cells. L. infantum infection induced changes in ENS, as evidenced by increases in the area of colonic enteric ganglia. Despite the absence of changes in the levels of Bf and LacB during the course of infection, the relative abundance of these bacteria was associated with parasite load and histological alterations.

MAIN CONCLUSIONS Our results indicate that L. infantum infection leads to important changes in the colon and suggest that bacteria in the GM play a protective role.

Key words: visceral leishmaniasis - L. infantum - intestinal tract - gut microbiota

The intestinal tract (IT) and gut microbiota (GM) have been recognised as important to the maintenance of overall health. Dysbiosis, the pathological alteration of GM composition, is present in several diseases, and not only in disorders affecting the intestine, such as inflammatory bowel disease. ${ }^{(1,2,3,4)}$ Among the several bacteria species that compose the GM, the Bifidobacterium (Bf) and Lactobacillus (LacB) genera are considered indicators of good intestinal health, and exhibit important immunomodulatory properties that are related to their use as probiotics in the treatment of several diseases. ${ }^{(5,6)}$ In addition,

doi: 10.1590/0074-02760200377

Financial support: FAPESB (grant numbers 4634/2012).

$A B$ and $M B N$ are senior investigator of $C N P q ; A D S$ received a fellowship from FAPESB.

FCP and MBG contributed equally to this work.

+ Corresponding author: gbaccan@ufba.br

(1) https://orcid.org/ 0000-0001-8479-508X

Received 16 July 2020

Accepted 12 November 2020 the beneficial properties of $\mathrm{Bf}$ and LacB during parasitic infections have been demonstrated in experimental models of trypanosomiasis, toxoplasmosis and malaria. ${ }^{(7,8,9)}$

Studies have revealed that the GM plays important local and systemic functions, including the regulation of intestinal permeability, nutrient absorption and immune response. Intestinal homeostasis can be impacted by interactions occurring between GM, local leukocytes, enterocytes and the enteric nervous system (ENS). ${ }^{(10,11)}$

Visceral leishmaniasis (VL) is a neglected disease that affects over 20,000 people annually worldwide, mainly in underdeveloped countries. ${ }^{(12)}$ It is caused by parasites of the genus Leishmania, which are transmitted via the bite of vectors, insects of the Phebotominae family. Parasites multiply in several organs, including the spleen and liver. As the immune response mounted by the host is generally not effective in destroying all parasites, VL can be fatal without pharmacological treatment.

Although the parasite cycle and pathophysiological mechanisms of VL have been well-characterised, the roles played by the IT and GM in the development of VL have not been fully elucidated. Studies involving dogs 
naturally infected by Leishmania spp. have shown histopathological alterations in the jejunum and colon, as well as changes in the expression of immune receptors, cytokines and immune cells. . $^{(13,14,15,16)}$ Among all VL experimental models, the Golden Syrian hamster Mesocricetus auratus is considered a superior animal model to evaluate the parasite-host relationship, immunopathogenesis, drug discovery and vaccine development studies; ${ }^{(17,18,19,20,21)}$ however these animals have not been used to investigate the effects of VL on IT and GM.

The present study aimed to investigate histopathological alterations in the IT of hamsters as well as changes in the levels of bifidobacteria (Bf) and lactobacilli (LacB) in the GM during the course of $L$. infantum infection.

\section{MATERIALS AND METHODS}

Animals, parasites and infection - Male Syrian golden hamsters (Mesocricetus auratus), aged six to eight weeks, were obtained from the Animal Care Facility of the Gonçalo Moniz Institute/Oswaldo Cruz Foundation (IGM-FIOCRUZ). The local Institutional Review Board for Animal Experimentation approved all procedures involving animals (Health Sciences Institute of the Federal University of Bahia) (CEUA-ICS/UFBA 034/2012). All experiments involving animals were conducted in accordance with the guidelines established by the Colégio Brasileiro de Experimentação Animal (COBEA) and the Conselho Nacional de Controle de Experimentação Animal (CONCEA).

L. infantum (MCAN/BR/00/BA262) promastigotes were cultivated in Schneider's insect Medium (Sigma Chemical Co., St Louis, MO, USA) supplemented with $20 \%$ inactivated fetal bovine serum, L-glutamine (2 $\mathrm{mM})$, penicillin $(100 \mathrm{U} / \mathrm{mL})$ and streptomycin $(100 \mu \mathrm{g} /$ $\mathrm{mL}$ ) at $23^{\circ} \mathrm{C}$ for 5-7 days until parasites reached stationary phase. Parasites were then washed three times with saline at 3,000 rpm for $10 \mathrm{~min}$, resuspended in saline and adjusted to $5 \times 10^{6}$ per $\mathrm{mL}$. Hamsters $(\mathrm{n}=20)$ were inoculated with $1 \times 10^{5}$ stationary-phase promastigotes intradermally in the ear. An identical number of uninfected hamsters were used as controls.

After infection, weekly evaluations included the evolution of body weight, the presence of clinical signs consistent with VL, including changes in hair appearance, paw arch and cachexia, as well as behavioral changes.

At four or eight months after infection, hamsters were euthanised by decapitation. Through vertical laparotomy, the liver, spleen and colon were removed, washed, measured and fixed. Stool samples were collected directly from the distal portion of the colon and stored at $-80^{\circ} \mathrm{C}$ until use.

Parasite load determination - Parasite load was evaluated by quantitative limiting dilution assay, as previously described by Lima et al. ${ }^{(22)}$ Briefly, the liver and spleen were aseptically removed from each hamster. Tissues were homogenised and diluted in Schneider's insect cell culture medium (Sigma, St. Louis, MO) supplemented with $10 \%$ heat-inactivated fetal bovine serum, $100 \mathrm{U} / \mathrm{mL}$ of penicillin and $100 \mu \mathrm{g} / \mathrm{mL}$ of streptomycin. Homogenated samples were serially diluted on a 96-well microtiter plate and incubated for seven days at $23^{\circ} \mathrm{C}$. Dilutions corresponding to wells exhibiting positive growth were used to estimate parasite load in the samples.

Histological processing and analysis - A 1-cm ring sectioned from the colon of each hamster was fixed in buffered paraformaldehyde (10\%) for $24 \mathrm{~h}$. Segments were dehydrated in ascending series of ethyl alcohol, diaphanised in xylol and embedded in paraffin to obtain semi-serial cross-sections measuring $5 \mu \mathrm{m}$, which were then stained with Hematoxylin and Eosin.

Morphometric analysis was performed via images captured by a digital camera (Olympus ${ }^{\circledR}$ SC $30,3.0$ Megapixel) coupled to an optical microscope (Olympus ${ }^{\circledR}$ BX43F - Minato-Ku, Japan). Measurements were obtained using Image-Pro Plus software version 4.5.0.29 (Media Cybernetics, Silver Spring, MD, USA). A 10× objective lens was used to capture images used to measure the total thickness of the intestinal wall, muscular tunic, submucosa, mucosa and the width and depth of crypts. Sixty-four measurements for each parameter were obtained throughout the circumference of each hamster's colon. ${ }^{(23,24)}$ A $100 \times$ objective lens was used to capture images used to measure the height and width (at three points) of 80 enterocytes, as well as the smallest and largest diameters of nuclei in these cells. ${ }^{(23,24)}$ Images of the myenteric plexus and submucosal plexus ganglia were captured using a $40 \times$ objective to measure the area of 10 ganglia from each plexus in all hamsters. These results are expressed as the average area, in $\mu \mathrm{m}^{2}$, of the ganglion profiles of both the myenteric and submucosal plexuses. ${ }^{(25)}$

Intraepithelial lymphocytes (IELs) were quantified using an optical microscope with the aid of a $40 \times \mathrm{ob}-$ jective. The number of cells was obtained by manual counts among a total of 2,500 epithelial cells in each hamster, which permitted the assessment of the number of IELs/100 epithelial cells. . $^{(23,24,25,26)}$

Histopathological analysis was performed to determine the presence of forms suggestive of amastigotes, ${ }^{(15)}$ as well as histoarchitectural changes in the colon wall, by direct microscopy using objective lenses of $4 \times, 10 \times$, $20 \times, 40 \times$ or $100 \times$. In addition, inflammatory cell infiltrate was evaluated according to the following classification criteria: (i) Intensity: corresponding to the number of inflammatory cells observed - Absent ( $0-9$ cells), Discreet (10-25 cells), Moderate (26-50 cells) or Intense (>50 cells); (ii) Distribution: - Focal: a single infiltrate in the visual field; Multifocal, more than one infiltrate in the visual field; Diffuse: inflammatory cells diffusely distributed in a visual field. ${ }^{(14,15,23,24,27,28)}$

Gut microbiota analysis - DNA was extracted from stool samples using the PowerFecal ${ }^{\circledR}$ DNA Isolation Kit (MO BIO Laboratories, Carlsbad, CA, USA) in accordance with the manufacturer's instructions. DNA concentrations were determined by absorbance at 260 $\mathrm{nm}$, and purity was estimated by determining the A260 to A280 ratio. Measurements were performed on a microvolume NanoDrop ${ }^{\circledR}$ ND-1000 spectrophotometer (NanoDrop Technologies, Wilmington, DE, USA). Purified DNA was stored at $-20^{\circ} \mathrm{C}$ until use. 
The relative quantification of $\mathrm{Bf}$ and $\mathrm{LacB}$ was accomplished by quantitative polymerase chain reaction (qPCR) using group-specific $16 \mathrm{~S}$ rRNA gene primers ${ }^{(29)}$ (Isogen Life Sciences, Netherlands) (Table I). A short segment of the 16S rRNA gene (200 bp) was specifically amplified by qPCR, using a conserved $16 \mathrm{~S}$ rRNA-specific primer pair (Table I) to determine the total amount of commensal bacteria in the feces (the so-called 'Eubacteria/Panbacteria' group). Using the same genomic DNA from each sample, qPCR was completed using groupspecific primers for the quantification of bacteria from Bifidobacterium spp. or Lactobacillus spp. (Table I).

Reactions were performed in glass capillary tubes using a LightCycler ${ }^{\circledR} 2.0$ thermocycler (Roche Applied Science, Alemanha). Reaction mixtures $(10 \mu \mathrm{L})$ were composed of PowerUp ${ }^{\mathrm{TM}}$ SYBR ${ }^{\mathrm{TM}}$ Green Master Mix (2X) (Thermo-Fisher Scientific, USA), $0.5 \mu \mathrm{L}$ of each of the specific primers (forward and reverse) at a concentration of $10 \mu \mathrm{M} / \mathrm{L}$ and $2 \mu \mathrm{L}$ of DNA template. A DNA concentration of $2 \mathrm{ng} / \mu \mathrm{L}$ was used in all reactions and the reaction volume was adjusted with MiliQ water to a final volume of $20 \mu \mathrm{L}$ per capillary tube according to the manufacturer's instructions. All reactions were performed in duplicate. Amplifications were performed using the following temperature profiles: one cycle at $95^{\circ} \mathrm{C}$ ( $2 \mathrm{~min}$ ), 40 cycles of denaturation at $95^{\circ} \mathrm{C}(15 \mathrm{~s})$, a primer annealing step $60^{\circ} \mathrm{C}(1 \mathrm{~min})$ and one final cycle at $95^{\circ} \mathrm{C}$ $(15 \mathrm{~s})$. Fluorescent products were detected in the last step of each cycle. Melt curve analysis was performed following amplification to distinguish between targeted and non-targeted PCR products. Melting curves were obtained by slow heating from 65 to $95^{\circ} \mathrm{C}$, with fluorescence measurements taken after every $1^{\circ} \mathrm{C}$ increase in temperature. A standard curve was generated for each set of primers. The qPCR amplification efficiency for all primer pairs was determined using the slope of linear regressions in a dilution series based on the following equation $\mathrm{E}=10(-1 /$ slope $)$. Relative quantification was calculated by the $2-\Delta \Delta \mathrm{Ct}$ method $^{(30)}$ (using the conserved 16S rRNA-specific primers (Total bacteria) as a reference gene). The results are expressed in terms of fold change over control.

Statistical analysis - Results are expressed as medians and interquartile ranges. The Kruskal-Wallis test was employed to analyse differences among more than two groups. Spearman's correlation coefficient was applied to investigate associations between the relative abundances of bacterial groups, parasite loads and histological parameters. All statistical tests were performed using GraphPad Prism software version 5.01 (GrahPad Software, Inc.). The significance level adopted was $5 \%$.

\section{RESULTS}

Detection of infection and parasite load - Infected (INF) and uninfected hamsters (CTL) showed similar body weight evolution four months after infection, while differences were noted after eight months (Fig. 1A). Most animals did not present clinicopathological signs, and infection was confirmed by the parasite load in the spleen and liver (Figs 1B, C, D). Splenomegaly was detected only at eight months of infection (Fig. 1C). No differences were observed in liver size between the INF and CTL hamsters (Fig. 1D). Parasite load was determined at both four and eight month timepoints in the spleen and liver (Fig. 1B). As expected, splenic parasite load was found to be higher at four months than at eight months post-infection, yet this was not the case in the liver (Fig. 1B).

Morphometric and histological alterations - Morphometric changes were noted in the colon wall of infected hamsters at both four and eight months (Table II). Hypertrophy of the muscular layer was evidenced, with a significant increase of $14.32 \%$ after eight months of infection. Hypertrophy was also seen in submucosal thickness, with increases of $15.31 \%$ and $24.49 \%$ after four and eight months of infection, respectively. On the other hand, atrophy in the mucosa was observed, with a reduction of $16.65 \%$ after four months and $15.23 \%$ at eight months post-infection (Table II).

Enterocyte height increased by $15.08 \%$ after four months of infection and enterocyte width increased by $26.39 \%$ at the eight-month timepoint. In addition, alterations in core diameters were observed, with an $11.58 \%$ increase in the largest nucleus diameter seen at eight post-infection (Table II).

In addition to morphometric changes in the colon wall, L. infantum infection also caused neuroplastic changes in the myenteric and submucosal plexuses (Fig. 2). At four and eight months after infection, increases were observed in the area $\left(\mu \mathrm{m}^{2}\right)$ of ganglions in both the myenteric and

TABLE I

Primers used to quantify bacterial populations by quantitative polymerase chain reaction (qPCR)

\begin{tabular}{lcc}
\hline Bacterial group & Oligonucleotide sequence & Reference \\
\hline \multirow{2}{*}{ Total bacteria } & F: 5' ACTCCTACGGGAGGCAGCAG 3' & \\
\hline Bifidobacterium spp. & R: 5' ATTACCGCGGCTGCTGG 3' & \\
\hline Lactobacillus spp. & F: 5' TCGCGTCYGGTGTGAAAG 3' \\
& R: 5' RCCACATCCAGCRTCCAC 3' & \\
\hline
\end{tabular}

F: forward; R: reverse. 
A

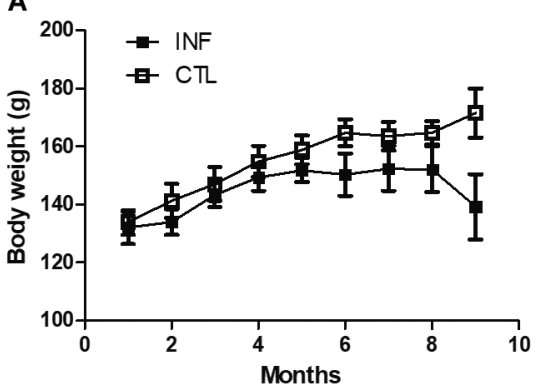

C

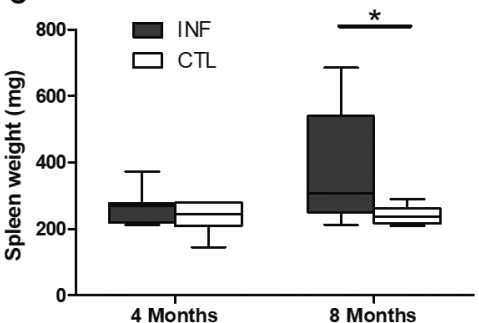

B
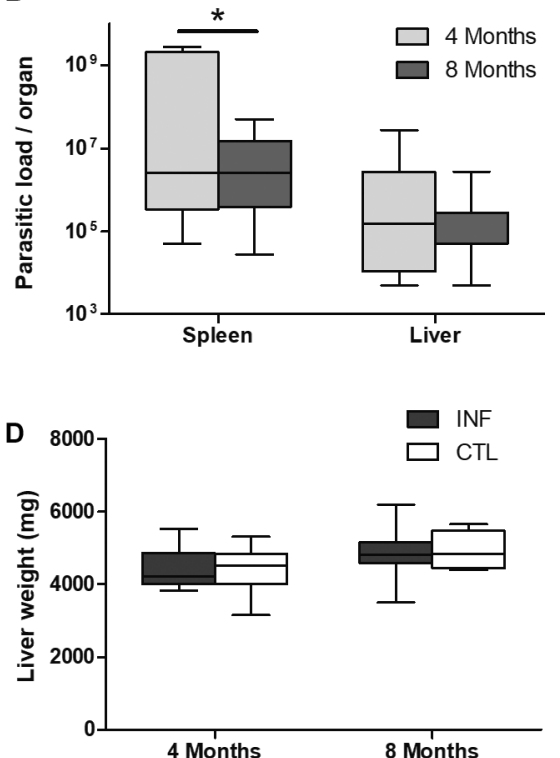

Fig. 1: anatomic characteristics and parasite load in hamsters infected or not by Leishmania infantum. Body weight of infected (INF) and control (CTL) hamsters over eight months (A). Parasitic load was evaluated by limiting dilutions at four and eight months in the spleen and liver (B). Spleen and liver weight were measured at four and eight months post-infection (C-D). *p $<0.05$.

TABLE II

Morphometry of the colon of Mesocricetus auratus hamsters infected or not by Leishmania infantum

\begin{tabular}{|c|c|c|c|c|c|}
\hline \multirow[b]{2}{*}{ Parameter $(\mu \mathrm{m})$} & & \multicolumn{2}{|c|}{ Four months post-infection } & \multicolumn{2}{|c|}{ Eight months post-infection } \\
\hline & & INF & CTL & INF & CTL \\
\hline $\begin{array}{l}\text { Muscular } \\
\text { tunic }\end{array}$ & \multirow{3}{*}{ Thickness } & $280.1(236.7-311.4)$ & $268.4(240.2-320.7)$ & $346.3(289.6-401.1)$ & $322.2(142.1-373.0)$ \\
\hline Submucosa & & $98.1(88.8-102.1)^{*}$ & $85.0(75.0-96.4)$ & $102.6(90.4-115.1)^{* *}$ & $80.9(70.3-91.8)$ \\
\hline Mucosa & & $338.9(273.7-394.7)^{*}$ & $394.8(309.8-454.4)$ & $336.9(276.7-378.3)$ & $388.2(339.4-474.5)$ \\
\hline \multirow{2}{*}{ Crypts } & Depth & $159.2(128.5-190.4)$ & $216.4(116.1-241.7)$ & $98.1(82.1-112.4)$ & $103.2(87.1-118.8)$ \\
\hline & Width & $54.5(47.6-69.8)$ & $75.6(48.8-86.7)$ & $47.9(40.4-52.71)$ & $43.3(36.8-51.6)$ \\
\hline \multirow{2}{*}{ Enterocytes } & Height & $18.7(17.3-20.84)^{* * *}$ & $15.8(13.7-18.8)$ & $22.3(18.6-24.1)$ & $20.2(17.6-22.4)$ \\
\hline & Width & $5.6(4.7-6.4)$ & $5.5(4.6-6.4)$ & $5.9(5.4-6.7)^{*}$ & $5.5(4.8-6.4)$ \\
\hline \multirow{2}{*}{$\begin{array}{l}\text { Enterocyte } \\
\text { nuclei }\end{array}$} & Largest-diameter & $4.6(3.7-5.4)$ & $4.5(3.6-5.4)$ & $5.9(5.1-6.6)^{* * *}$ & $4.6(3.8-5.4)$ \\
\hline & Smallest-diameter & $3.3(2.8-3.8)$ & $3.1(2.6-3.5)$ & $3.4(2.9-3.7)$ & $3.5(3.1-3.8)$ \\
\hline
\end{tabular}

Data expressed as medians (interquartile range). Results compared by the Kruskal-Wallis test (Results in bold indicate statistical differences compared to the control. CTL: control animals; INF: infected hamsters; *: $p<0.05 ; * *: p<0.001$.

submucosal plexuses. In the myenteric plexus, an increase of $48.17 \%$ and $45.52 \%$ was noted at four and eight months, respectively (Fig. 2A). In the submucosal plexus, the area increased by $97.57 \%$ and $67.15 \%$ after four and eight months of infection, respectively (Fig. 2B). No significant changes were seen in the number of ganglia. In addition to neuroplastic changes, other important histopathological findings were the presence of diffuse inflammatory infiltrate in the lamina propria and within the ganglia of the submucosal plexus, characterising periganglionitis and ganglionitis, respectively (Fig. 2D).
Histopathological analysis of the colonic mucosa revealed that $L$. infantum infection induced cellular and tissue changes at both the four and eight month timepoints (Fig. 3A-D). Forms suggestive of amastigotes were seen inside macrophages in the lamina propria (Fig. 3D). Semiquantitative histopathological analysis indicated a significant loss of colonic mucosa histoarchitecture, the presence of diffuse inflammatory infiltrate in the submucosa and lamina propria, moderate inflammatory infiltrate in the crypts, and a significant reduction in the number of goblet cells (Table III). 

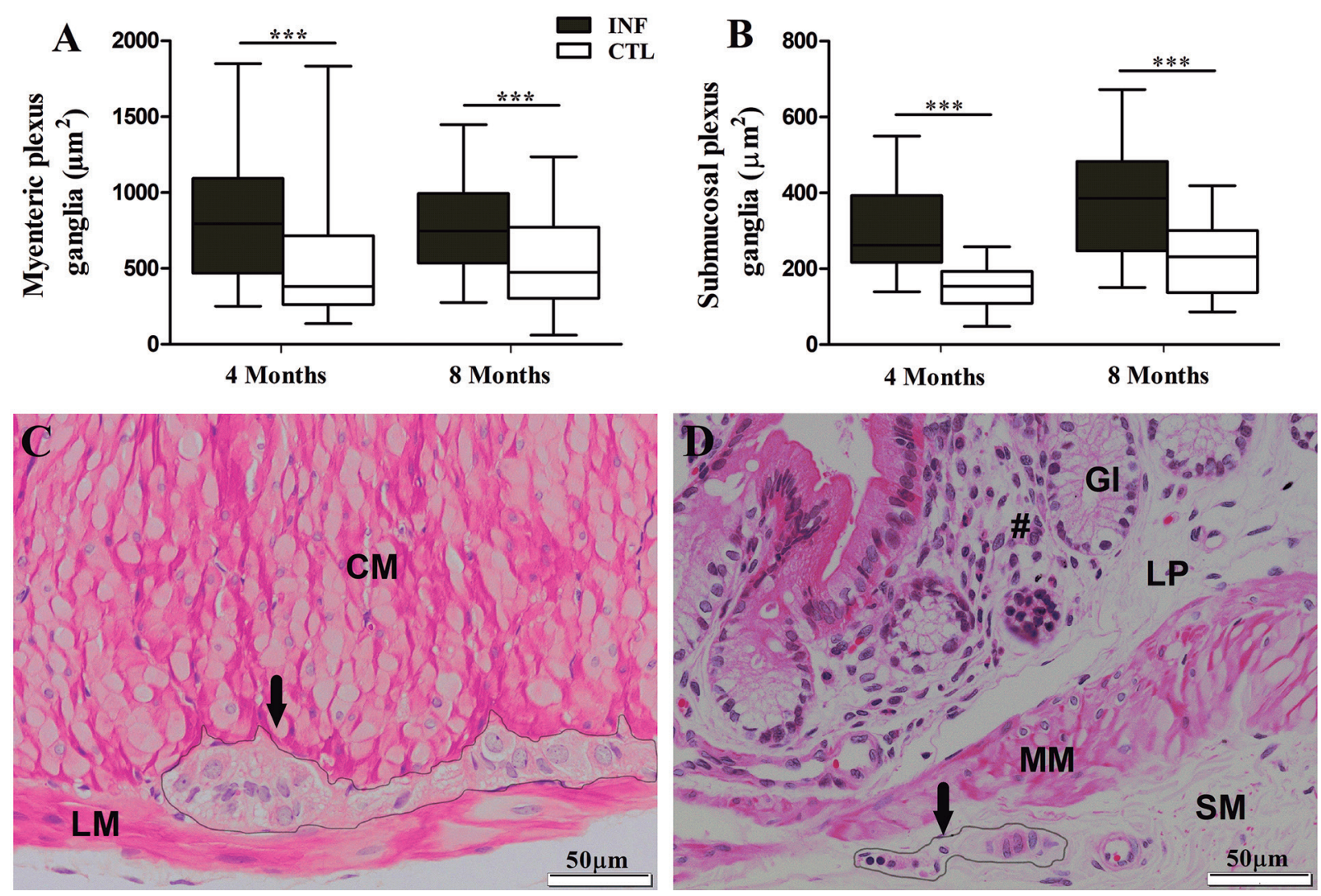

Fig. 2: ganglion profiles $\left(\mu \mathrm{m}^{2}\right)$ of the myenteric (A) and submucosal (B) plexuses. Histological staining of the myenteric plexus (black arrow) between the longitudinal (LM) and circular (CM) layers of the external musculature (C). Histological analysis of the submucosal plexus (black arrow) in the submucosa (D) of the colon wall in hamsters infected by Leishmania infantum four months post-infection, with a notable increase in inflammatory infiltrate (\#) in the lamina propria (LP). MM: muscularis mucosa; SM: submucosa; GI: intestinal glands in the Crypts of Lieberkühn. Objective lens: 40x. Data expressed as medians (interquartile range). $* * * p<0.001$.

In addition, our results indicate that $L$. infantum infection resulted in changes in the distribution of IELs, as evidenced by an increase of $18.35 \%$ in the colon mucosa of infected hamsters at four months compared to uninfected animals (Fig. 4).

Bifidobacteria and lactobacilli levels - Relative levels of $\mathrm{Bf}$ and LacB were determined by qPCR (Fig. 5). The amplification efficiencies for the SYBR Green I assays were obtained by plotting the CT values against the target DNA starting quantity. Using the formula $\mathrm{E}$ $=10(-1 /$ slope $)$, the efficiencies for the individual assays ranged from $96.3-98.7 \%$.

No differences were found in the relative abundance of $\mathrm{Bf}$ or LacB when comparing between the INF and CTL hamsters, at either four or eight months of infection. However, in the INF group, a significant increase was observed in $\mathrm{Bf}$ levels at eight months compared to four months after infection (Fig. 5).

Associations between parasite load, histological parameters and bifidobacteria and lactobacilli levels - $\mathrm{Bf}$ levels were found to be negatively correlated with parasite load, as well as the area of myenteric and submucosal plexus ganglia (Table IV). The relative levels of LacB were also negatively associated with the area of the myenteric and submucosal plexus ganglia, and positively correlated with the loss of the histoarchitecture of the mucosa wall (Table IV).

\section{DISCUSSION}

The present results demonstrate morphological alterations in the colon of hamsters infected by $L$. infantum, including histoarchitectural loss, increased inflammatory infiltrate and changes in ENS components. Despite similarities in the relative abundance of $\mathrm{Bf}$ and LacB between infected and control animals, these bacteria were nonetheless associated with lower parasite load and histological alterations in the colon of infected hamsters. Our results also indicate that $L$. infantum infection induced neuroplastic changes in ENS, as evidenced by increases in the area of ganglia in both the myenteric and submucosal plexuses.

Histological analysis revealed that $L$. infantum infection induced hypertrophy of the mucosal and atrophy of the submucosal layers of the Golden Syrian hamster colon. Animals infected by intradermal inoculation or by the bite of insect vectors have been used to study the immunopathological mechanisms of this disease, as well as in vaccine development, mainly due to the reproduction of clinicopathological aspects of human VL. $.^{(18,20,21,31)} \mathrm{De}-$ 

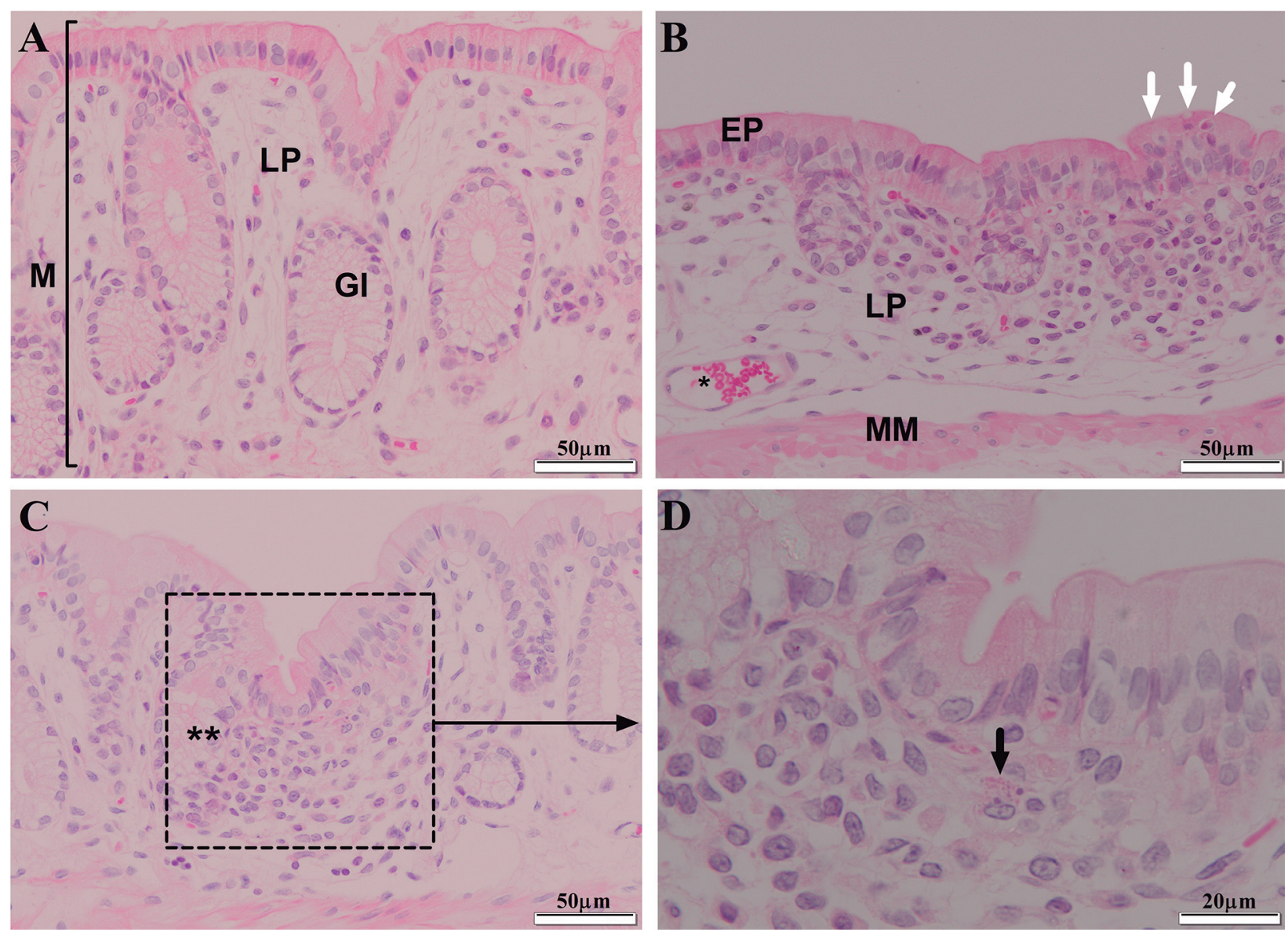

Fig. 3: photomicrographs of cross-sections of the colon wall from uninfected (A) and infected hamsters (B-D) at eight months post-infection. (A) histoarchitecture of control animals; (B) infected hamsters demonstrating loss of wall histoarchitecture, presence of intraepithelial lymphocytes (white arrows), diffuse inflammatory infiltrate with a predominance of mononuclear cells in the lamina propria (LP), hypercellularity, presence of cells with plasma cell morphology and congested vessels $(*)$; (C) hypercellularity and presence of focal inflammatory infiltrate $(* *)$; (D) inflammatory focus containing polymorphonuclear and mononuclear cells, as well as forms suggestive of amastigotes in the cytoplasm of a macrophage in the lamina propria (black arrow). Objective lens: 40x (A-C) and 100x (D). EP: epithelium; M: mucosa; LP: lamina propria; MM: muscularis mucosa; GI: intestinal glands in Crypts of Lieberkühn.

spite wide use of this experimental model, little has been reported regarding the morphometric changes in the IT induced by $L$. infantum. A study revealed that BALB/c mice inoculated intravenously with amastigotes of $L$. infantum (chagasi) exhibited atrophy of the ileum wall after 45 days of infection. ${ }^{(32)}$ In addition, hamsters and mice inoculated with other species of Leishmania also revealed morphometric changes in the IT. ${ }^{(23,24)}$

Alterations in the ENS have been described in other infections. Infection by Toxoplasma gondii was shown to result in a reduction in the number and area of ganglia in the myenteric plexus. ${ }^{(25)}$ Notably, T. gondii infection also induced enteric neuroplasticity. ${ }^{(33,34)}$ In contrast, neuroplastic changes caused by Trypanosoma cruzi, including those observed in the megaesophagus ${ }^{(35)}$ and megacolon, ${ }^{(36,37)}$ may compromise IT function. Infection by $T$. cruzi has been reported to result in increased colon size and diameter, ${ }^{(35)}$ as well as the death and hypertrophy of myenteric neurons, ${ }^{(38)}$ increased inflammatory infiltrate, myositis, periganglionitis, ganglionitis and elevated levels of pro-inflammatory cytokines. ${ }^{(35)}$
Regarding localised immune response, infection by L. infantum provoked an increase in immune cell migration to the lamina propria, which likely led to the observed loss of mucosal histoarchitecture and diffuse inflammation. This inflammatory infiltrate could be related to the cryptitis, periganglionitis and ganglionitis observed in this study. Moreover, the presence of suggestive forms of $L$. infantum amastigotes inside macrophages in intestinal mucosa corroborates these histopathological findings. Unfortunately, we were unable to identify the presence of amastigotes in the intestine of the infected hamsters evaluated herein; future studies should make an attempt to confirm this association. Previous studies in other experimental models of VL have shown the presence of $L$. infantum amastigotes in the liver, spleen and small and large intestine. ${ }^{(8,9,10,11,12,13,14,15}$ $, 16,28,32,39)$ Periganglionitis and ganglionitis, characterised by the infiltration of immune cells into the neural microenvironment, may occur primarily or secondarily to a wide variety of diseases. ${ }^{(36,37,40,41,42,43,44)}$ Inflammatory infiltrates in myenteric plexus ganglia compatible with 
TABLE III

Semiquantitative histopathological analysis of colon mucosa in uninfected and infected hamsters

\begin{tabular}{|c|c|c|c|c|}
\hline \multirow[b]{2}{*}{ Parameter } & \multicolumn{2}{|c|}{ Four months } & \multicolumn{2}{|c|}{ Eight months } \\
\hline & INF & CTL & INF & CTL \\
\hline Histoarchitectural loss & $2.0(1.0-3.0)^{*}$ & $1.0(1.0-1.75)$ & $2.0(2.0-3.0)^{* * *}$ & $1.0(1.0-2.0)$ \\
\hline Inflammatory infiltrate & $2.0(2.0-3.0)^{* * *}$ & $1.5(1.0-2.0)$ & $2.0(2.0-3.0)^{* * *}$ & $1.5(1.0-2.0)$ \\
\hline Cryptitis & $2.0(1.0-2.0)^{* *}$ & $1.0(0.25-1.0)$ & $2.0(1.0-2.0)^{* * *}$ & $1.0(1.0-2.0)$ \\
\hline Goblet cells & $1.0(0.0-2.0)^{* *}$ & $2.0(2.0-3.0)$ & $2.0(0.0-3.0)$ & $1.0(1.0-3.0)$ \\
\hline
\end{tabular}

Scores expressed as medians (interquartile range). Results compared by the Kruskal-Wallis test (Results in bold indicate statistical differences compared to the control. CTL: control animals; INF: infected hamsters; *: $p<0.01 ; * *: p<0.001$.
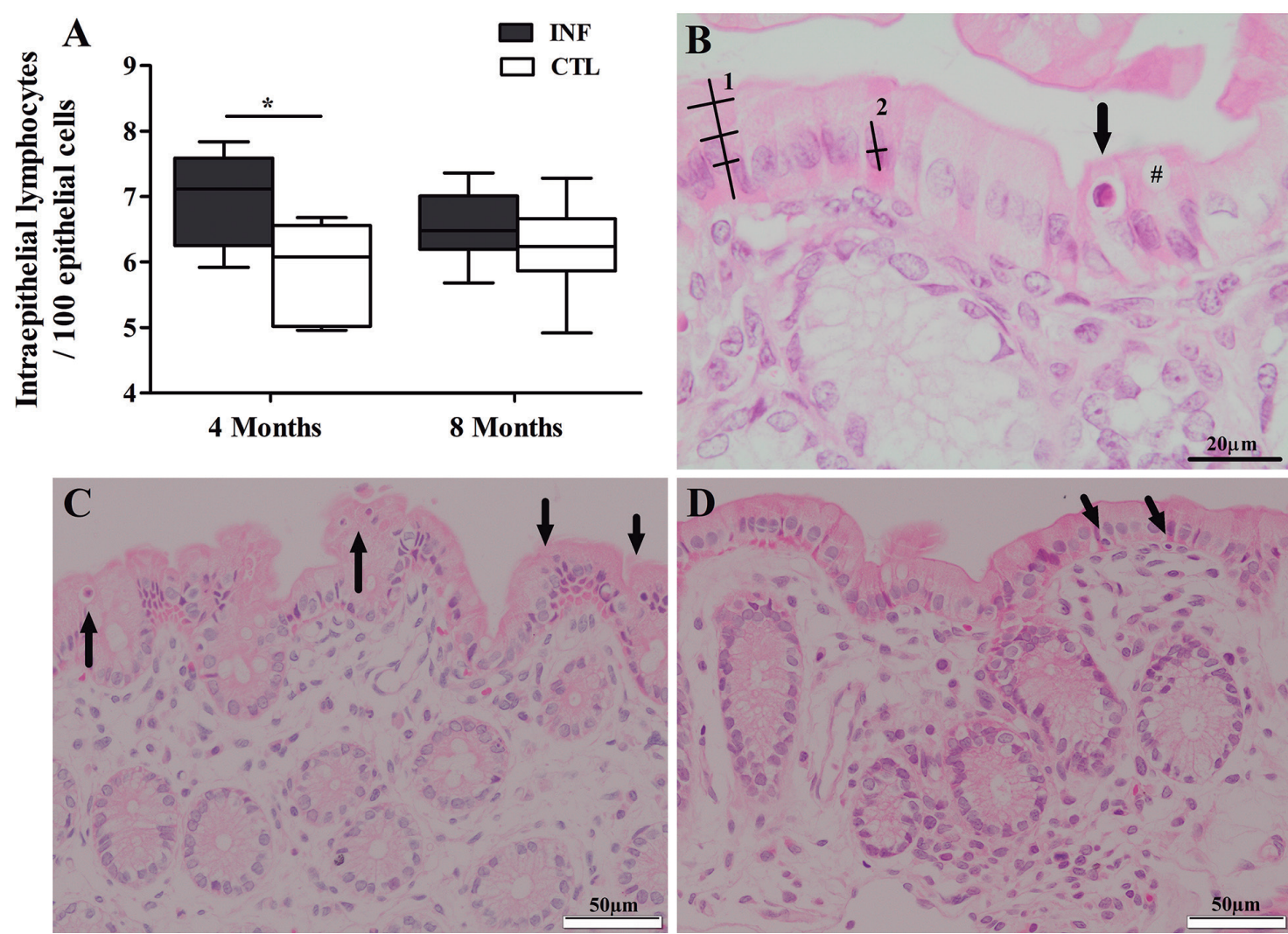

Fig. 4: cellular alterations seen in the colon epithelium of uninfected (CTL) and infected (INF) hamsters. (A) Intraepithelial lymphocytes and epithelial cells quantified by optical microscopy (40x). Distribution of intraepithelial lymphocytes (arrows) in intestinal epithelium of CTL (B) and INF hamsters at four (C) and eight (D) months post-infection. (B) schematic measurement of height and width of enterocytes (1) and nuclei (2). \#: goblet cell. Data expressed as medians (interquartile range). ${ }^{*} \mathrm{p}<0.05$.

periganglionitis and ganglionitis have been reported during infection induced by L. infantum in $\operatorname{dog} \mathrm{s}^{(15)}$ and L. (V.) braziliensis in mice. ${ }^{(23)}$ These results corroborate our findings, since the presence of Leishmania sp. amastigotes correlates with tissue injury that could damage the ENS. Ganglionitis can cause inflammatory neuropathy and lead to the neuronal degeneration. ${ }^{(40,45)}$ Among the intestinal alterations reported in leishmaniasis are the formation of leishmaniotic granuloma, ulcerative colitis, degeneration in the crypt epithelium, ${ }^{(15,39)}$ chronic lymphadenitis and enteritis. ${ }^{(28)} \mathrm{A}$ common element in all of these changes is the presence of diffuse inflammatory infiltrate in the intestinal wall containing mononuclear and polymorphonuclear cells..$^{(14,15)}$ These findings lead us to suggest that the morphometric and neuroplastic alterations observed herein were likely triggered by the histopathological changes.

The integrity of the colonic epithelium was evaluated by measuring enterocyte height and width, as well as cellular nuclei, in addition to the distribution of intraepithelial lymphocytes. The number (18.3\% increase) and distribution of IELs was observed to change in the 
Bifidobacterium spp
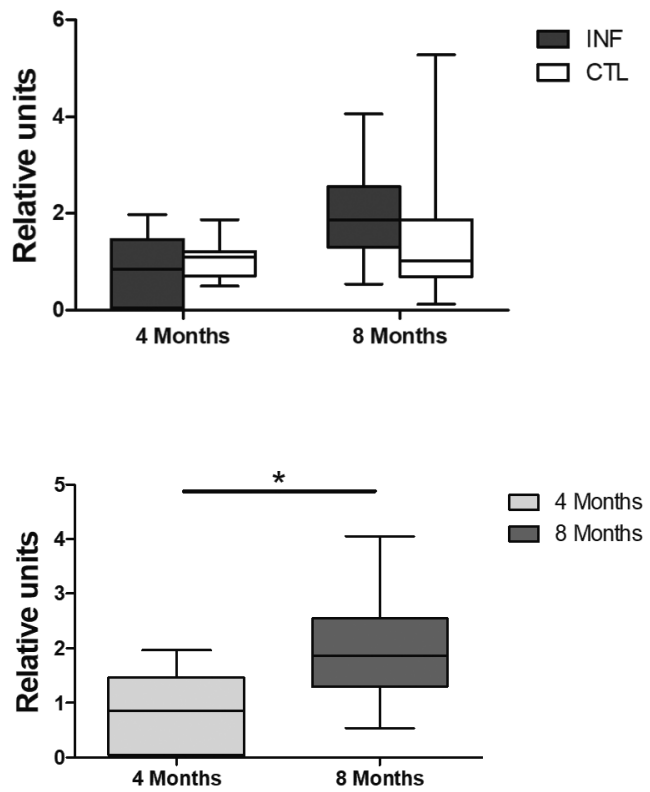

Lactobacillus spp
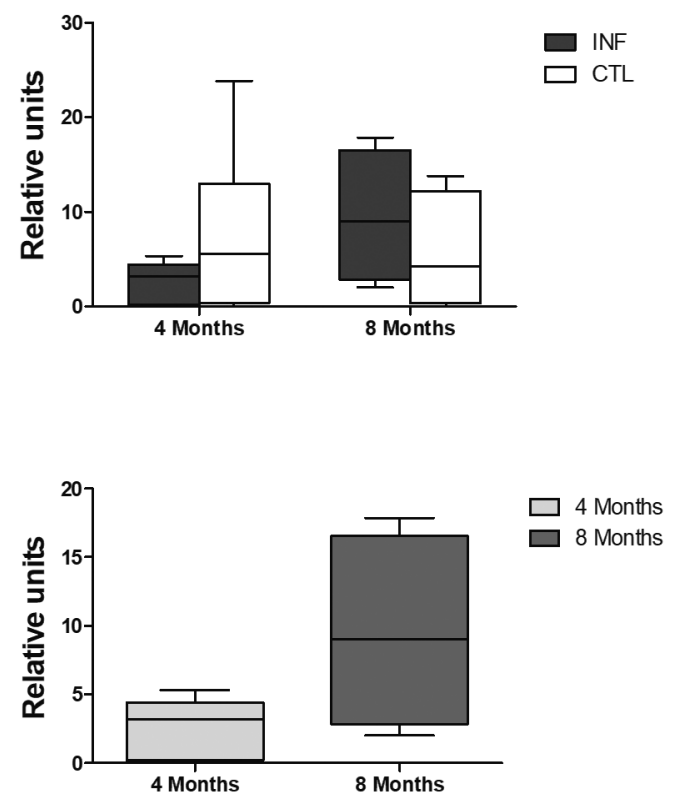

Fig. 5: relative abundance of Bifidobacterium spp. and Lactobacillus spp. in the gut microbiota of hamsters uninfected (CTL) and infected by Leishmania infantum (INF). Lower panels represent bacterial abundance at four and eight months post-infection in INF animals only. Bacterial levels determined by quantitative polymerase chain reaction (qPCR). Data expressed as medians (interquartile range). ${ }^{*} p<0.05$.

TABLE IV

Correlations between disease parameters and relative abundance of Bifidobacterium spp and Lactobacillus spp

\begin{tabular}{lcccc}
\hline & \multicolumn{2}{c}{ Bifidobacteria } & Lactobacilli \\
\cline { 2 - 5 } Parameter & $\mathrm{r}$ & $\mathrm{p}$ & $\mathrm{r}$ & $\mathrm{p}$ \\
\hline Body weight & 0.3093 & 0.0799 & -0.2545 & 0.2788 \\
\hline Spleen weight & -0.1409 & 0.4342 & 0.1662 & 0.4837 \\
\hline Liver weight & 0.2276 & 0.2027 & -0.1692 & 0.4757 \\
\hline Splenic parasite load & $\mathbf{- 0 . 5 2 5 3}$ & 0.0252 & -0.5030 & 0.1383 \\
\hline Liver parasite load & -0.2714 & 0.2760 & -0.4182 & 0.2291 \\
\hline Loss of mucosal histoarchitecture & 0.1610 & 0.1095 & $\mathbf{0 . 2 0 4 7}$ & 0.0411 \\
\hline Cryptitis & $\mathbf{0 . 2 6 9 2}$ & 0.0067 & 0.1488 & 0.1577 \\
\hline Area of myenteric plexus ganglia & $\mathbf{- 0 . 2 9 7 6}$ & 0.0001 & $\mathbf{- 0 . 3 1 7 7}$ & $<0.0001$ \\
\hline Area of submucosal plexus ganglia & $\mathbf{- 0 . 3 6 9 3}$ & $<0.0001$ & $\mathbf{- 0 . 3 4 7 4}$ & $<0.0001$ \\
\hline
\end{tabular}

r: Spearman's correlation coefficient; p: statistical significance level.

colon of infected hamsters at four months. All studies reporting on tissue changes in IT arising from Leishmania sp infection detected changes in the ratio of lymphocytes to epithelial cells. ${ }^{(16,23,24)}$ In the megaesophagus and megacolon, neuronal degeneration has been associated with enteric ganglion invasion by cytotoxic $\mathrm{T}$ cells. ${ }^{(37)}$ Herein, the alterations seen in the myenteric and submucosal plexuses occurred simultaneously with histopathological changes, i.e. increases in the number of IELs and reduced goblet cells.
Injury to the submucosal plexus results in an imbalance between the immune system and intestinal epithelium, ${ }^{(46,47)}$ which is reflected in the GM..$^{(10,11)}$ To investigate whether the GM could interact with the immune system and the ENS to reduce the impact associated with $L$. infantum infection, the relative abundance of Bifidobacterium spp. and Lactobacillus spp. was evaluated. These groups of bacteria were selected as they are considered indicators of good intestinal health that present important immunomodulatory properties and have had a long 
history of use as probiotics in the treatment of several diseases. ${ }^{(5,6)}$ In addition, several studies have evidenced the beneficial properties of $\mathrm{Bf}$ and $\mathrm{LacB}$ during parasitic infections in experimental models of trypanosomiasis, toxoplasmosis and malaria. ${ }^{(7,8,9)}$ Importantly, no changes were found in the relative abundance of $\mathrm{Bf}$ or $\mathrm{LacB}$, perhaps due to low numbers of parasites in the hamster infection protocol, which did not lead to the development of severe disease. A recent meta-taxonomic analysis of GM in stool samples performed in Indian VL patients ${ }^{(48)}$ found no changes in GM compared to healthy individuals. Changes in GM and/or gut permeability could lead to microbial translocation and contribute to the rise in LPS plasma levels observed in VL patients, which are related to T-cell activation and increase in pro-inflammatory cytokines. ${ }^{(49)}$ Lamour et al. ${ }^{(50)}$ evaluated GM using next-generation sequencing in mice infected with $L$. major in two different experimental models of Cutaneous Leishmaniasis (CL) and detected marked changes in faecal bacterial composition after infections, which differed between the self-healing and non-healing mice. (50) Another study investigated the role of GM in the development of CL using germ-free animals, reporting that the absence of GM at the beginning of infection may influence lesion size as well as immune response. . $^{(1,52)}$

Although our results did not indicate changes in the relative abundance of $\mathrm{Bf}$ and $\mathrm{LacB}$, we did find associations between these bacteria present in the GM and parasite load as well as histological parameters, supporting the notion that these bacteria could have a host-protective role in infection. Furthermore, the observed decrease in spleen parasite load at eight months compared to the earlier 4-month timepoint post-infection, together with the inverse effect observed in relative $\mathrm{Bf}$ levels, points to the role of GM in parasitic control. While it is plausible that the relationship between relative $\mathrm{Bf}$ abundance and parasite load could be related to competitive exclusion and immunomodulatory aspects, ${ }^{(5,53)}$ we were unable to determine a causal relationship, since a higher parasite load could induce decreases in Bf levels as well.

The present study is limited by the fact that changes in the relative abundance of other groups of bacteria were not evaluated, nor in the diversity of the composition of the GM.

In conclusion - Our results suggest that $L$. infantum infection results in morphometric, neuroplastic and histopathological changes in the colon in Golden Syrian hamsters. While experimental infection was not found to promote changes in the relative abundance of $\mathrm{Bf}$ and $\mathrm{LacB}$, these bacteria could be associated with the immunological control of parasite load and colon injury, which warrants further study. Our findings are consistent with those in the literature indicating the importance of the IT and GM in the host defense response.

\section{ACKNOWLEDGEMENTS}

To Fabíola Ramos Jesus for critical manuscript review. We would also like to thank Andris K Walter for English language revision and manuscript copyediting services.

\section{AUTHORS' CONTRIBUTION}

Conceptualisation - FCP, MBG and GCB; investigation - FCP, MBG, ADS, AIL and LC; resources - AB and GCB; original draft preparation - FCP and MBG; review and editing - MS, MBN, AB and GCB; supervision - GCB.

\section{REFERENCES}

1. Fyhrquist N. The human microbiota and its relationship with allergies. Gastroenterol Clin North Am. 2019; 48(3): 377-87.

2. Serrano-Villar S, Herrera S, Martínez-Sanz J. HIV, cancer, and the microbiota: common pathways influencing different diseases. Front Immunol. 2019; 10: 1466.

3. Jamshidi P, Hasanzadeh S, Tahvildari A, Farsi Y, Arbabi M, Mota $\mathrm{JF}$, et al. Is there any association between gut microbiota and type 1 diabetes? A systematic review. Gut. 2019; 11(1): 49.

4. Sudo N. Role of gut microbiota in brain function and stress-related pathology. Biosci Microbiota Food Health. 2019; 38(3): 75-80.

5. Alessandri G, Ossiprandi MC, MacSharry J, Van Sinderen D, Ventura M. Bifidobacterial dialogue with its human host and consequent modulation of the immune system. Front Immunol. 2019; 10: 2348

6. Sanders ME, Merenstein DJ, Reid G, Gibson GR, Rastall RA. Probiotics and prebiotics in intestinal health and disease: from biology to the clinic. Nat Rev Gastroenterol Hepatol. 2019; 16(10): 605-16.

7. Okolo CC, Nweze NE, Eze IJ. Hematobiochemical and immunological responses of rats treated with multi-strain probiotics and infected with Trypanosoma brucei. Probiotics Antimicrob Proteins. 2019; 12(3): 952-60.

8. Ribeiro CM, Costa VM, Gomes MIFV, Golim MA, Modolo JR, Langoni $\mathrm{H}$. Effects of synbiotic-based Bifidobacterium animalis in female rats experimentally infected with Toxoplasma gondii. Comp Immunol Microbiol Infect Dis. 2011; 34(2): 111-4.

9. Martínez-Gómez F, Ixta-Rodríguez O, Aguilar-Figueroa B, Hernández-Cruz R, Monroy-Ostria A. Lactobacillus casei ssp. rhamnosus enhances non specific protection against Plasmodium chabaudi AS in mice. Salud Publica Mex. 2006; 48(6): 498-503.

10. Yoo BB, Mazmanian SK. The enteric network: interactions between the immune and nervous systems of the gut. Immunity. 2017; 46(6): 910-26.

11. De Vadder F, Grasset E, Holm LM, Karsent, G, Macpherson AJ, Olofsson LE, et al. Gut microbiota regulates maturation of the adult enteric nervous system via enteric serotonin networks. Proc Natl Acad Sci USA. 2018; 115(25): 6458-63.

12. WHO - World Health Organization. Weekly epidemiological record. 2018; 93(40): 521-40.

13. Pinto AJ, Figueiredo MM, Silva FL, Martins T, Michalick MS, Tafuri WL. Histopathological and parasitological study of the gastrointestinal tract of dogs naturally infected with Leishmania infantum. Acta Vet Scand. 2011; 53(1): 67.

14. Figueiredo MM, Amorim IF, Pinto A, Barbosa VS, de Jesus PL, Deoti B, et al. Expression of Toll-like receptors 2 and 9 in cells of dog jejunum and colon naturally infected with Leishmania infantum. BMC Immunol. 2013; 14(1): 1-12.

15. Silva DT, Neves MF, Queiroz NMGPD, Spada JCP, Alves ML, Flóro SM, et al. Correlation study and histopathological description of intestinal alterations in dogs infected with Leishmania infantum. Rev Bras Parasitol Vet. 2016; 25(1): 24-36.

16. Silva DTD, Alves ML, Spada JCP, Silva ACD, Silveira RDCVD, Oliveira TMFDS, et al. T lymphocytes and macrophages in the intestinal tissues of dogs infected with Leishmania infantum. Rev Bras Parasitol Vet. 2017; 26(2): 159-70. 
17. Saini S, Rai AK. Hamster, a close model for visceral leishmaniasis: opportunities and challenges. Parasite Immunol. 2020; 42(10): 12768.

18. Aslan H, Dey R, Meneses C, Castrovinci P, Jeronimo SMB, Oliva $\mathrm{G}$, et al. A new model of progressive visceral leishmaniasis in hamsters by natural transmission via bites of vector sand flies. $\mathrm{J}$ Infect Dis. 2013; 207(8): 1328-38.

19. Da Silva RA, Tavares NM, Costa D, Pitombo M, Barbosa L, Fukutani K, et al. DNA vaccination with KMP11 and Lutzomyia longipalpis salivary protein protects hamsters against visceral leishmaniasis. Acta Trop. 2011; 120(3): 185-90.

20. Melby PC, Chandrasekar B, Zhao W, Coe JE. The hamster as a model of human visceral leishmaniasis: progressive disease and impaired generation of nitric oxide in the face of a prominent Th1like cytokine response. J Immunol. 2001; 166(3): 1912-20.

21. Requena JM, Soto M, Doria MD, Alonso C. Immune and clinical parameters associated with Leishmania infantum infection in the golden hamster model. Vet Immunol Immunopathol. 2000; 76(34): $269-81$.

22. Lima HC, Bleyenberg JA, Titus RG. A simple method for quantifying Leishmania in tissues of infected animals. Parasitol Today. 1997; 13(2): 80-2.

23. Dos Santos AGA, De Lima LL, Mota CA, Gois MB, Fernandes ACBS, Silveira TGV, et al. Insights of Leishmania (Viannia) braziliensis infection in golden hamster (Mesocricetus auratus) intestine. Biomed Pharmacother. 2018; 106: 1624-32.

24. Santos AGAD, Ferlini JDP, Vicentino SL, Lonardoni MVC, Sant'Ana DMG, Melo GAND. Alterations induced in the ileum of mice upon inoculation with different species of Leishmania: a preliminary study. Rev Soc Bras Med Trop. 2018; 51(4): 537-41.

25. Pastre MJ, Casagrande L, Gois MB, Pereira-Severi LS, Miqueloto CA, Garcia JL, et al. Toxoplasma gondii causes increased ICAM-1 and serotonin expression in the jejunum of rats $12 \mathrm{~h}$ after infection. Biomed Pharmacother. 2019; 114: 108797.

26. Sant'Ana DM, Góis MB, Zanoni JN, da Silva AV, da Silva CJ, Araújo EJ. Intraepithelial lymphocytes, goblet cells and VIP-IR submucosal neurons of jejunum rats infected with Toxoplasma gondii. Int J Exp Pathol. 2012; 93(4): 279-86.

27. Oberhuber G, Granditsch G, Vogelsang H. The histopathology of coeliac disease: time for a standardized report scheme for pathologists. Eur J Gastroenterol Hepatol. 1999; 11(10): 1185-94.

28. Figueiredo MM, Deoti B, Amorim IF, Pinto AJ, Moraes A, Carvalho CS, et al. Expression of regulatory T cells in jejunum, colon, and cervical and mesenteric lymph nodes of dogs naturally infected with Leishmania infantum. Infect Immun. 2014; 82(9): 3704-12.

29. Mujico JR, Baccan GC, Gheorghe A, Díaz LE, Marcos A. Changes in gut microbiota due to supplemented fatty acids in diet-induced obese mice. Br J Nutr. 2013; 110(4): 711-20.

30. Livak KJ, Schmittgen TD. Analysis of relative gene expression data using real-time quantitative PCR and the $2-\Delta \Delta \mathrm{CT}$ method. Methods. 2001; 25(4): 402-8.

31. Da Silva RA, Tavares NM, Costa D, Pitombo M, Barbosa L, Fukutani K, et al. DNA vaccination with KMP11 and Lutzomyia longipalpis salivary protein protects hamsters against visceral leishmaniasis. Acta Trop. 2011; 120(3): 185-90.

32. Souza KD, Fernandes EPA, Dos Santos AGA, de Lima LL, Gonzaga WFKM, Xander P, et al. Infection by Leishmania (Leishmania) infantum chagasi causes intestinal changes B-1 cells dependent. Parasite Immunol. 2019; 41(9): e12661.
33. Hermes-Uliana C, Pereira-Severi LS, Luerdes RB, Franco CLM, Da Silva AV, de Almeida AEJ, et al. Chronic infection with Toxoplasma gondii causes myenteric neuroplasticity of the jejunum in rats. J Auton Nerv Syst. 2011; 160(1-2): 3-8.

34. de Almeida AEJ, Zaniolo LM, Vicentino SL, Góis MB, Zanoni JN, da Silva AV, et al. Toxoplasma gondii causes death and plastic alteration in the jejunal myenteric plexus. World J Gastroenterol. 2015; 21(16): 4829.

35. Nogueira-Paiva NC, Fonseca KS, Vieira PMA, Diniz LF, Caldas IS, Moura SAL, et al. Myenteric plexus is differentially affected by infection with distinct Trypanosoma cruzi strains in Beagle dogs. Mem Inst Oswaldo Cruz. 2014; 109(1): 51-60.

36. da Silveira ABM, Lemos EM, Adad SJ, Correa-Oliveira R, Furness JB, Reis DDA. Megacolon in Chagas disease: a study of inflammatory cells, enteric nerves, and glial cells. Hum Pathol. 2007; 38(8): 1256-64.

37. Da Silveira ABM, Freitas MAR, De Oliveira EC, Neto SG, Luquetti AO, Furness JB, et al. Neuronal plasticity of the enteric nervous system is correlated with chagasic megacolon development. Parasitology. 2008; 135(11): 1337.

38. Vazquez BP, Vazquez TP, Miguel CB, Rodrigues WF, Mendes MT, de Oliveira CJF, et al. Inflammatory responses and intestinal injury development during acute Trypanosoma cruzi infection are associated with the parasite load. Parasit Vectors. 2015; 8(1): 206.

39. Adamama-Moraitou KK, Rallis TS, Koytinas AF, Tontis D, Plevraki K, Kritsepi M. Asymptomatic colitis in naturally infected dogs with Leishmania infantum: a prospective study. Am J Trop Med Hyg. 2007; 76(1): 53-7.

40. De Giorgio R, Guerrini S, Barbara G, Stanghellini V, De Ponti $\mathrm{F}$, Corinaldesi R, et al. Inflammatory neuropathies of the enteric nervous system. Gastroenterology. 2004; 126(7): 1872-83.

41. Ekblad E, Bauer AJ. Role of vasoactive intestinal peptide and inflammatory mediators in enteric neuronal plasticity. Neurogastroenterol Motil. 2004; 16: 123-8.

42. Qin JLR, Raes J, Arumugam M, Burgdorf KS, Manichanh C, Nielsen T, et al. A human gut microbial gene catalogue established by metagenomic sequencing. Nature. 2010; 464(7285): 59-65.

43. Bajer L, Kverka M, Kostovcik M, Macinga P, Dvorak J, Stehlikov $\mathrm{Z}$, et al. Distinct gut microbiota profiles in patients with primary sclerosing cholangitis and ulcerative colitis. World J Gastroenterol. 2017; 23(25): 4548-58.

44. Roubalová R, Procházková P, Papežová H, Smitka K, Bilej M, Tlaskalová-Hogenová $\mathrm{H}$. Anorexia nervosa: gut microbiota-immune-brain interactions. Clin Nutr. 2020; 39(3): 676-84.

45. Spiller R, Grundy D, editors. Pathophysiology of the enteric nervous system: a basis for understanding functional diseases. John Wiley \& Sons. 2008.

46. Toumi F, Neunlist M, Denis MG, Oreshkova T, Laboisse CL, Galmiche JP, et al. Vasoactive intestinal peptide induces IL-8 production in human colonic epithelial cells via MAP kinase-dependent and PKA-independent pathways. Biochem Biophys Res Commun. 2004; 317(1): 187-91.

47. Neunlist M, Van Landeghem L, Mahé MM, Derkinderen P, Des Varannes SB, Rolli-Derkinderen M. The digestive neuronal-glialepithelial unit: a new actor in gut health and disease. Nat Rev Gastroenterol Hepatol. 2013; 10(2): 90-100.

48. Lappan R, Classon C, Kumar S, Singh OP, De Almeida RV, Chakravarty $\mathrm{J}$, et al. Meta-taxonomic analysis of prokaryotic and eukaryotic gut flora in stool samples from visceral leishmaniasis cases and endemic controls in Bihar State India. PLoS Negl Trop Dis. 2019; 13(9): e0007444. 
49. Santos-Oliveira JR, Regis EG, Leal CR, Cunha RV, Bozza PT, Da-Cruz AM. Evidence that lipopolisaccharide may contribute to the cytokine storm and cellular activation in patients with visceral leishmaniasis. PLoS Negl Trop Dis. 2011; 5(7): e1198.

50. Lamour SD, Veselkov KA, Posma JM, Giraud E, Rogers ME, Croft S, et al. Metabolic, immune, and gut microbial signals mount a systems response to Leishmania major infection. J Proteome Res. 2015; 14(1): 318-29.

51. de Oliveira MR, Tafuri WL, Nicoli JR, Vieira EC, Melo MN,
Vieira LQ. Influence of microbiota in experimental cutaneous leishmaniasis in Swiss mice. Rev Inst Med Trop São Paulo. 1999; 41(2): 87-94.

52. Oliveira MRD, Tafuri WL, Afonso LCC, Oliveira MAPD, Nicoli JR, Vieira EC, et al. Germ-free mice produce high levels of interferon-gamma in response to infection with Leishmania major but fail to heal lesions. Parasitology. 2005; 131(4): 477.

53. O'Callaghan A, Van Sinderen D. Bifidobacteria and their role as members of the human gut microbiota. Front Microbiol. 2016; 7: 925. 